\title{
Influence of the quenching rate and step-wise cooling temperatures on microstructural and tensile properties of PER72 $\mathbb{R}$ Ni-based superalloy
}

\author{
Paul Le Baillif ${ }^{1}$, Pascal Lamesle ${ }^{1}$, Denis Delagnes ${ }^{1}$, Vincent Velay ${ }^{1}$, Christian Dumont $^{2}$, and Farhad Rézaï-Aria ${ }^{1}$ \\ ${ }^{1}$ Université de Toulouse; Mines Albi, INSA, UPS, ISAE; ICA (Institut Clément Ader), Campus Jarlard, 81013 Albi \\ Cedex 09, France \\ 2 Aubert \& Duval, BP. 1, 63770 Les Ancizes, France
}

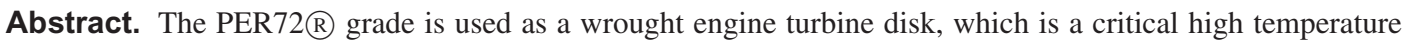
component. During the heat treatment process, residual stresses are generated during the quench, which may lead to irreversible damages on the workpiece. The aim of this study is to better understand the mechanisms involved in the residual stress generation. Therefore, the influence of quenching conditions on the high temperature tensile properties and the multi-scale microstructure evolutions are investigated after cooling.

PER72 $\cap$ specimens are annealed above the solvus temperature, directly on the servo-hydraulic testing machine. Three quenching rates are used: $30^{\circ} \mathrm{C} / \mathrm{min}, 120^{\circ} \mathrm{C} / \mathrm{min}$, and $300^{\circ} \mathrm{C} / \mathrm{min}$. For each condition, the cooling is interrupted at $1000^{\circ} \mathrm{C}, 850^{\circ} \mathrm{C}, 600^{\circ} \mathrm{C}$ and $20^{\circ} \mathrm{C}$ to perform isothermal tensile test. Specimens are post-mortem analysed. On one hand the fracture surface is investigated using SEM. On the other hand the microstructure evolution was observed and quantified at different scales using SEM directly on the bulk or after the chemical extraction of precipitation. The precipitation size and volume fraction statistics, X-Ray diffraction for the crystallography and composition of the different phases are investigated.

It was shown that the testing temperature does not significantly influence the $\gamma^{\prime}$ distribution of particles. Conversely, the $\gamma^{\prime}$ precipitation is strongly influenced by the cooling rate. Notably, the average size, the distance between particles as well as the number density of $\gamma^{\prime}$ precipitates are significantly modified by the cooling rate. Changes in tensile properties are related to microstructural.
\end{abstract}

\section{Introduction}

Superalloys have been especially developed for high temperature application, in particular for aeronautical industry. For instance, PER72 $\cap$ is a nickel-based superalloy used in turbine disk manufacturing. In service, the temperature of these parts can rise $600{ }^{\circ} \mathrm{C}$ and the rotation speed is about $60000 \mathrm{rpm}$. Turbine disk are thus critical helicopter engine components.

The excellent high strength properties of PER72 $\mathbb{R}$ are mainly due to $\gamma^{\prime}$ phase precipitates. The precipitation occurs through a heat treatment including an annealing, a quench and then two ageings. In particular, the quench is performed for a defined and controlled cooling rate. Quenching conditions mostly control the precipitate size and distribution [1-4]. However, due to the massive geometry of the disk and the poor thermal conductivity, the cooling rate in the core is lower than at the surface. The temperature in the part is thus heterogeneous during the quench, and the local mechanical properties can be significantly different. The differential dilatations as well as the differences in metallurgical transformation caused by the different cooling conditions induce residual stresses. Residual stresses can induce plasticity that may initiate cracks $[5,6]$. For those specific applications, it is of the utmost importance to develop alloys that have fine and homogeneous multi-scale microstructures.

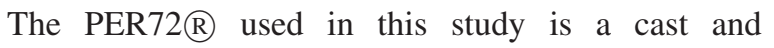
wrought polycrystalline superalloy. At a smaller scale, precipitation is observed and consists of ordered and coherent $\gamma^{\prime}\left(\mathrm{Ni}_{3}(\mathrm{Ti}, \mathrm{Al})\right)$ phase particles distributed in the $\gamma$ matrix $[4,7,8]$. Precipitates are observable under three distinct categories [1,2,9]: the primary $\gamma^{\prime}$ particles are intergranular big-sized precipitates $(1-10 \mu \mathrm{m})$ whereas the secondary $\gamma^{\prime}$ correspond to an intragranular homogenous precipitation. Their shape can be spherical, cubic or irregular, with a diameter ranging from 50 to $500 \mathrm{~nm}$. Finally, the tertiary $\gamma^{\prime}$ are smaller intragranular precipitates located between the secondary $\gamma^{\prime}$. These spherical-shaped precipitates are the finest, ranging from few nanometers to approximately $50 \mathrm{~nm}$. Secondary and tertiary $\gamma^{\prime}$ particles are strongly involved in the strengthening mechanism.

The aim of the study presented below is on one hand to reproduce in the laboratory different cooling conditions directly on specimens, and thus measure the tensile mechanical properties evolution during cooling from annealing temperature. Then, the conditions that result in a substantial loss of properties are determined. On the other hand multi-scale microstructural analysis is carried out to evaluate $\gamma^{\prime}$ distribution variation during the quench. The differences in precipitation characteristics are related to the mechanical properties. 
Table 1. Composition of the PER72@ grade (wt \%).

\begin{tabular}{|l|l|l|l|l|l|l|l|l|l|l|}
\hline $\mathrm{Ni}$ & $\mathrm{Cr}$ & $\mathrm{Co}$ & $\mathrm{Ti}$ & $\mathrm{Mo}$ & $\mathrm{Al}$ & $\mathrm{W}$ & $\mathrm{Si}$ & $\mathrm{C}$ & $\mathrm{B}$ & $\mathrm{Zr}$ \\
\hline bal & 16.2 & 14.5 & 5.0 & 2.9 & 2.5 & 1.2 & 0.1 & 0.02 & 0.02 & 0.04 \\
\hline
\end{tabular}

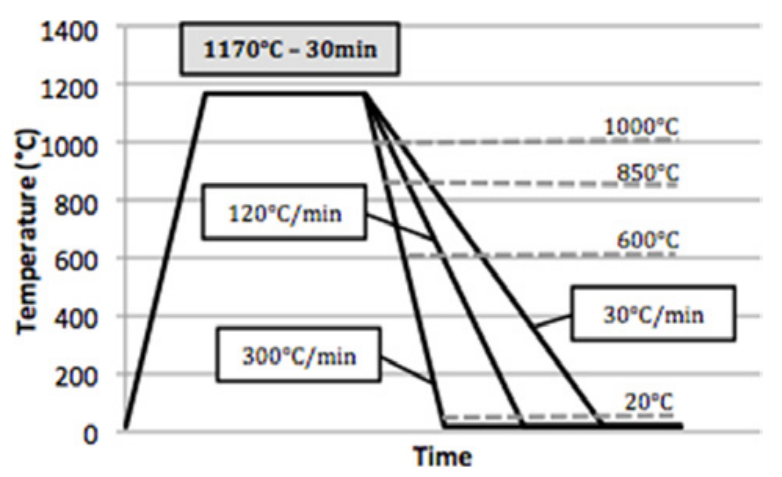

Figure 1. Heat treatment schedule.

\section{Material and experimental procedures}

\subsection{Chemical composition}

The PER72 $($ alloy was extracted from a forged disk, which was produced by vacuum induction melting, electro-slag remelting, vacuum arc remelting and finally forging. Sheet blank samples were cut from the disk in the tangential direction. The mechanical testing specimens have been machined from samples. The chemical composition of the material is given in Table 1.

\subsection{Heat treatment and experimental schedule}

After a supersolvus annealing at $1170{ }^{\circ} \mathrm{C}$ held for 30 minutes, three cooling rates $-30^{\circ} \mathrm{C} / \mathrm{min}, 120^{\circ} \mathrm{C} / \mathrm{min}$ and $300^{\circ} \mathrm{C} / \mathrm{min}$ - were studied. For each cooling rate, the quench was interrupted at different intermediate temperatures to perform isothermal mechanical tensile tests. Four temperatures $-1000^{\circ} \mathrm{C}, 850{ }^{\circ} \mathrm{C}, 600^{\circ} \mathrm{C}$ and $20^{\circ} \mathrm{C}$ - have been selected. These experimental conditions are described in Fig. 1.

In order to investigate more precisely the microstructural evolution, additional samples have been heattreated ("stress-free" samples). After the same supersolvus annealing, some were quenched at larger range of cooling rates : $23^{\circ} \mathrm{C} / \mathrm{min}, 170^{\circ} \mathrm{C} / \mathrm{min}, 315^{\circ} \mathrm{C} / \mathrm{min}$ and $525^{\circ} \mathrm{C} / \mathrm{min}$. Other were aged between 7 and 30 days at high temperatures - from $750{ }^{\circ} \mathrm{C}$ to $1150{ }^{\circ} \mathrm{C}$.

\subsection{Mechanical tests}

An advanced mechanical testing setup has been developed to perform tensile test during the heat treatment. Annealing and quench were carried out directly on the mechanical testing machine using a high frequency induction-heating generator. The heating and cooling profiles were controlled and recorded using thermocouples welded on the surface of each specimen.

Tensile tests were performed using a computercontrolled MTS hydraulic testing machine supported by MTS Multi-Purpose Testware. They were carried out at controlled strain rate $-10^{-3} \mathrm{~s}^{-1}-$ using a high temperature extensometer.

At the end of the mechanical test, the specimen is quenched rapidly by turning the power of the inductionheating off and applying a cold compressed air flow in order to "freeze" the microstructure.

\subsection{Microstructure analysis}

Two samples were taken from the centre of each specimen. The "stress-free" samples were also split into two parts.

The first samples were prepared for observations of the microstructure. They were polished with $\mathrm{SiC}$ papers till 1200 grid and then abrasive solutions. The $\gamma^{\prime}$ phase and grain boundaries was observed after etching samples using aqua regia. Between each step, samples were rinsed in ethanol and blow-dried.

The microstructure is then investigated at different scales. The grain size was measured using a Keyence numerical microscope. At smaller scale, $\gamma^{\prime}$ precipitates were examined using a FEI ${ }^{\mathrm{TM}}$ Nova Nano 450 scanning electron microscope (SEM). The operating voltage was $20 \mathrm{kV}$ and the magnification was between 5 and $10^{5}$. The precipitate size distribution is analysed using the Aphelion $^{\mathrm{TM}}$ software.

Moreover, the second samples were used to extract the $\gamma^{\prime}$ phase. The $\gamma$ matrix was dissolved by electrochemistry [10], and the precipitates were extracted using a Beckmann-Coulter Aventi J30i centrifuge. The acceleration provided by the centrifugation was about $100000 \mathrm{~ms}^{-2}$. The composition of $\gamma$ and $\gamma^{\prime}$ phases were then determined separately using inductively coupled plasma optical emission spectrometry (ICP-OES). The lattice parameter of each phase has been determined using Philips X'Pert X-ray diffractometer.

\section{Results and discussion}

\subsection{Tensile tests}

\subsubsection{Effect of the interrupted cooling temperature}

Figure 2 shows tensile tests results obtained at $1000{ }^{\circ} \mathrm{C}$, $850^{\circ} \mathrm{C}, 600^{\circ} \mathrm{C}$ and $20^{\circ} \mathrm{C}$ for a cooling rate of $300^{\circ} \mathrm{C} / \mathrm{min}$. Similar curves were obtained for the other cooling rates of the experimental schedule. The yield stress and Young modulus decrease according to the temperature. Moreover, the temperature significantly influences the mechanical behaviour: at high temperature, the viscous effects shown in Fig. 2 should be taken into account in the mechanical behaviour. The fracture mode is intergranular (Fig. 3a). Conversely, at $600^{\circ} \mathrm{C}$ and $20^{\circ} \mathrm{C}$, the strain hardening effect seems to control the mechanical behaviour. The fracture surface presents a transgranular rupture over the whole surface as shown in Fig. 3b. At $850{ }^{\circ} \mathrm{C}$, the maximum stress is reached for low strain levels - decreasing from 3 to $1 \%$ according to the cooling rate. At this temperature, 


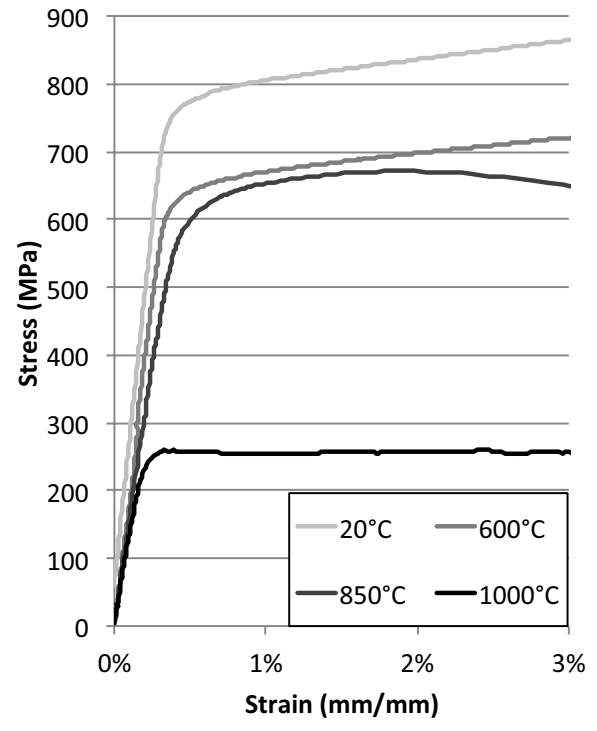

Figure 2. Tensile test results obtained at different temperatures between $20^{\circ} \mathrm{C}$ and $100^{\circ} \mathrm{C}$, for a cooling rate of $300^{\circ} \mathrm{C} / \mathrm{min}$.

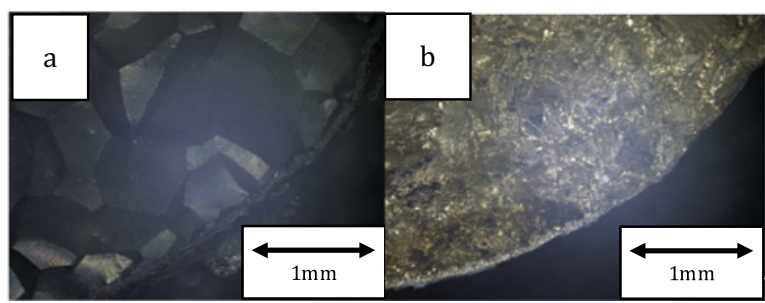

Figure 3. Fracture surface at $1000^{\circ} \mathrm{C}$ (a) and $600^{\circ} \mathrm{C}(\mathrm{b})$.

two different zones can be observed in the fracture surface: an intergranular area for the major part of the fracture surface and a transgranular zone for a portion of $30 \%$ of the surface (Fig. 4). The early intergranular crack initiation and propagation observed at that temperature (Fig. 5) could explain the decreasing stress.

\subsubsection{Effect of the cooling rate}

The effect of cooling rate for the different investigated temperatures is plot in Fig. 6. At $1000^{\circ} \mathrm{C}$, the quenching conditions have no influence on the mechanical properties. On the contrary, the experimental results show that the conventional yield stress significantly increases with the cooling rate at lower temperatures. Obviously the cooling rate has a strong impact on the mechanical properties. Consequently this parameter should be taken into account in the prediction of mechanical properties of bulky parts.

\subsection{Relationship between $\gamma^{\prime}$ precipitation and tensile properties}

\subsubsection{Effect of the interrupted cooling temperature}

The Fig. 7 shows two SEM images from samples heattreated at the same cooling rate $\left(120^{\circ} \mathrm{C} / \mathrm{min}\right)$. The first one was cooled until $1000{ }^{\circ} \mathrm{C}$, the other one until room temperature. The $\gamma^{\prime}$ average diameter is found to be approximately the same for both samples.

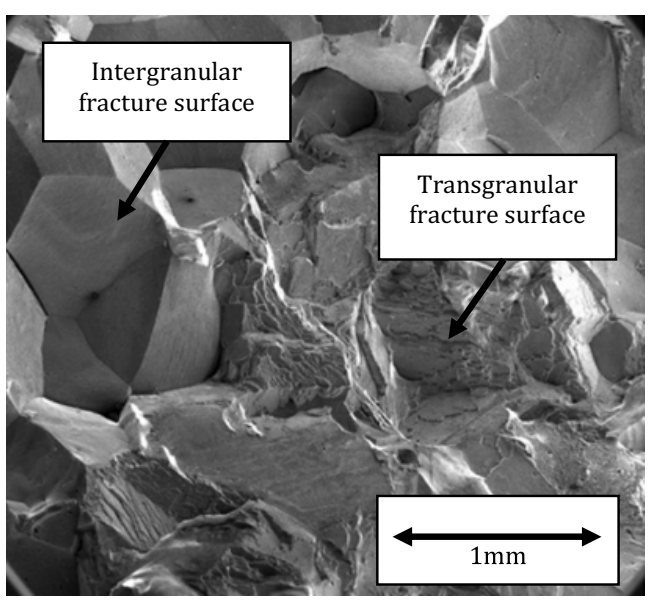

Figure 4. Fracture surface observed on post-mortem specimen, after a tensile test at $850^{\circ} \mathrm{C}$ (SEM observation).

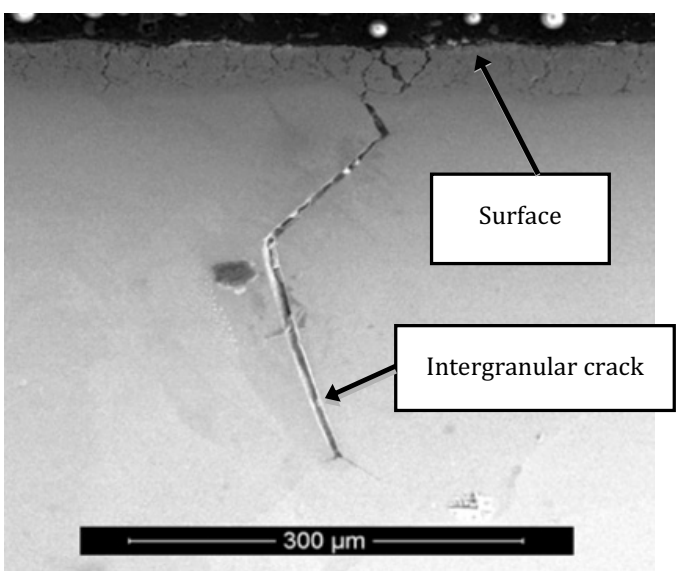

Figure 5. Intergranular crack initiation -Tensile test at $850^{\circ} \mathrm{C}$, interrupted for a strain level of $1 \%$ (SEM observation).

For a selected cooling rate, the $\gamma^{\prime}$ precipitation does not significantly change although the testing temperature is different. Indeed, the final temperature after cooling does not seem to have a significant influence on the microstructure under $1000^{\circ} \mathrm{C}$. This result can be supported by the fact that the precipitation kinetics is controlled by a diffusional process [2]. Consequently, the main $\gamma^{\prime}$ precipitation domain is situated over $1000^{\circ} \mathrm{C}$ for the PER72 $\mathrm{R}$ grade as indicated in the TTT diagram previously determined by [2].

\subsubsection{Effect of cooling rate}

Unlike the findings given in the previous paragraph, the Fig. 8 shows a significant evolution of the $\gamma^{\prime}$ precipitation at room temperature for the three selected cooling rates. The secondary $\gamma^{\prime}$ average diameter is plot as a function of cooling rates in the Fig. 9. The faster is the cooling, the smaller is the precipitate average size.

Furthermore, the weight fraction can be estimated using the electro-chemical extraction technique. Using the chemical composition and the lattice parameter of each phase, the experimental volume fraction of precipitates can be calculated. One the other hand, assuming that all titanium and aluminium have diffused in $\gamma^{\prime}$ phase, a 
a) Tensile tests at $1000^{\circ} \mathrm{C}$

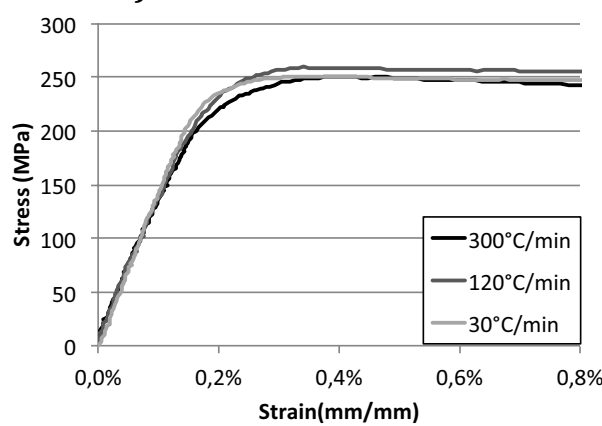

c) Tensile tests at $600^{\circ} \mathrm{C}$

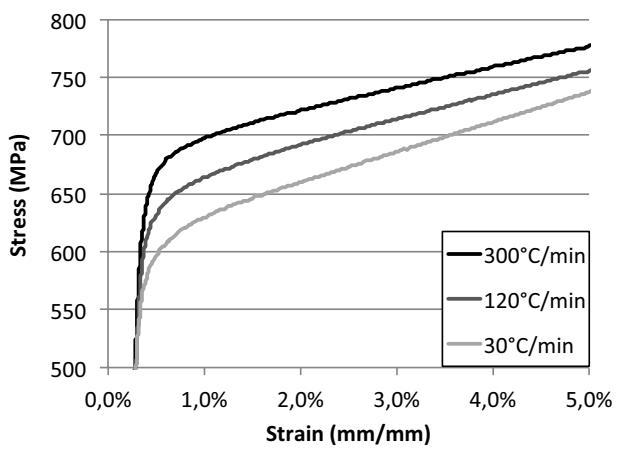

b) Tensile tests at $850^{\circ} \mathrm{C}$

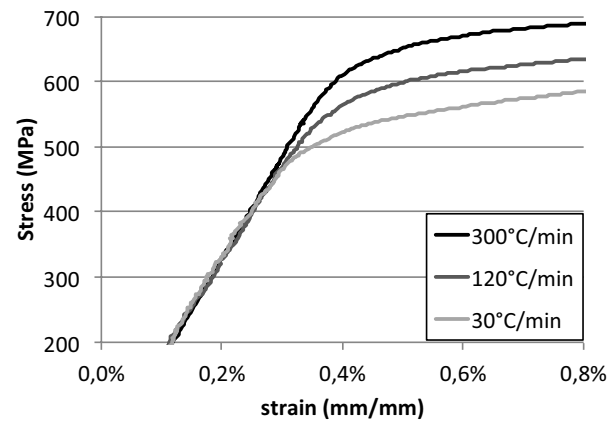

d) Tensile tests at $20^{\circ} \mathrm{C}$

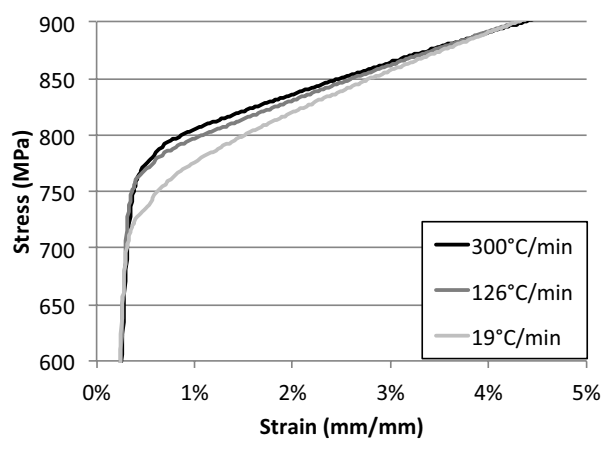

Figure 6. Tensile test for different cooling rates at $1000^{\circ} \mathrm{C}$ a), $\left.850^{\circ} \mathrm{C} \mathrm{b}\right), 600^{\circ} \mathrm{C}$ c) and $20^{\circ} \mathrm{C} \mathrm{d}$ ).
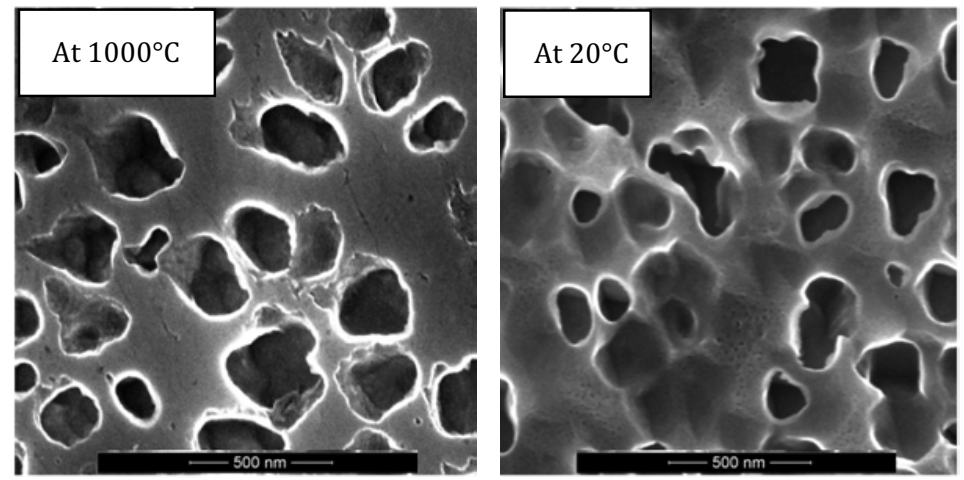

Figure 7. Effect of temperature for a $120^{\circ} \mathrm{C} / \mathrm{min}$ cooling rate - SEM observations.

theoretical value of the maximum volume fraction can be derived $-37.9 \%$. This result is in agreement with the precipitation simulation result given by Matcalc ${ }^{\mathrm{TM}}$. Moreover, the experimental volume fraction determined for the sample maintained 7 days at $750{ }^{\circ} \mathrm{C}$ is in the same order of magnitude $-37.5 \%$.

The Table 2 shows the evolution of the volume fraction of $\gamma^{\prime}$ particles with the cooling rate. Similarly as for the average size, the volume fraction decreases with increasing cooling rates. The experimental values are lower than the theoretical values (by 5 to 10 points). Consequently, the asquenched PER72 $\mathrm{R}$ grade is far from the thermodynamic equilibrium state given by the phase diagram.

It has been shown that the volume fraction and average size of precipitates are strongly influenced by the cooling rate (Fig. 9 and Table 2). Considering these two parameters, the number density of particles can be estimated as accurately described in reference [12].
Figure 10 shows the increase of the number density according to the cooling rate. In the same figure, the conventional yield strength is also plotted. The increase of yield strength can be directly connected to the particles number density variation. Indeed, considering the average size of secondary $\gamma^{\prime}$ particles (few tens of nanometers to more than $100 \mathrm{~nm}$ ), the main mechanism involved in the strengthening may be the Orowan bypass of particles by dislocation as already observed in several nickel superalloys. Therefore, $\gamma^{\prime}$ particles, which form a spatial arrangement of obstacles to the movement of dislocations, are a microstructural feature of primary importance. Specifically, the average distance between particles and/or the number density seem to be the most relevant parameters.

It is therefore important that the future mechanical model takes into account this significant change in number density (of about a factor of 10 for an increase of 


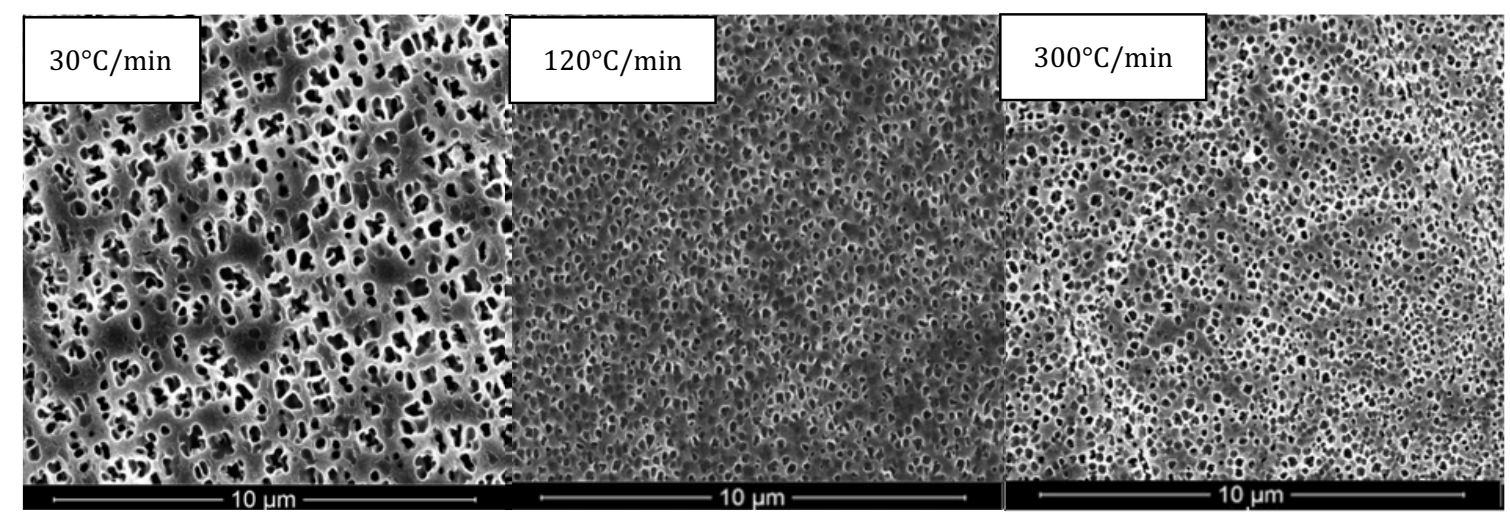

Figure 8. Effect of cooling rate on the $\gamma^{\prime}$ precipitation - SEM images of as-quench samples.

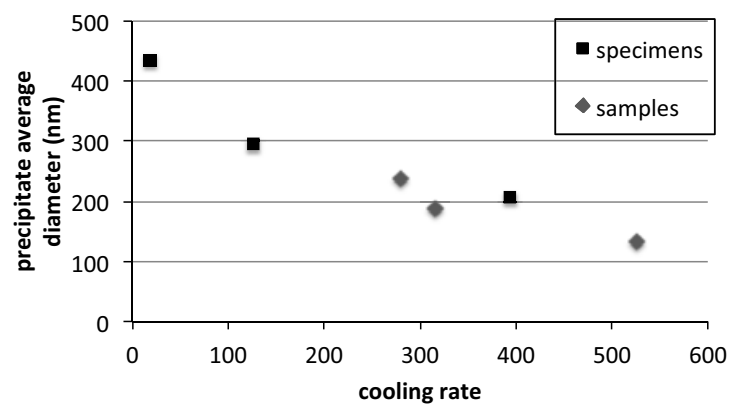

Figure 9. Influence of the cooling rate on the $\gamma^{\prime}$ average diameter.

Table 2. Precipitates volume fraction estimated for different cooling rates (cooling from $1170^{\circ} \mathrm{C}$ to room temperature).

\begin{tabular}{|l|l|}
\hline Cooling rate & Volume fraction (\%) \\
\hline $23^{\circ} \mathrm{C} / \mathrm{min}$ & 32.3 \\
\hline $170^{\circ} \mathrm{C} / \mathrm{min}$ & 28.7 \\
\hline $315^{\circ} \mathrm{C} / \mathrm{min}$ & 27.8 \\
\hline $525^{\circ} \mathrm{C} / \mathrm{min}$ & 27.2 \\
\hline
\end{tabular}

the cooling rate from $50{ }^{\circ} \mathrm{C} / \mathrm{min}$ to $400{ }^{\circ} \mathrm{C} / \mathrm{min}$ ) in the prediction of residual stresses after cooling. This is one of the two main outlooks of this work.

\section{Conclusion and outlooks}

The influence of cooling conditions from a supersolvus

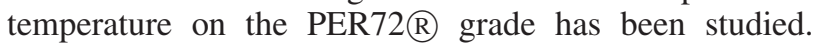
The microstructural aspects and tensile properties were particularly investigated. Specifically, a high temperature testing setup was developed to perform the tensile test at a given temperature during the cooling after annealing. Different testing temperatures (cooling interruption) and cooling rate were analyzed. The main conclusions can be summarized as follows:

i) The temperature of the tensile test (interrupted cooling after supersolvus annealing) as well as the cooling rate very significantly affects the tensile properties.

ii) Conversely, the microstructure including the $\gamma^{\prime}$ precipitation observed at room temperature does not seem to be influenced by the testing temperature.

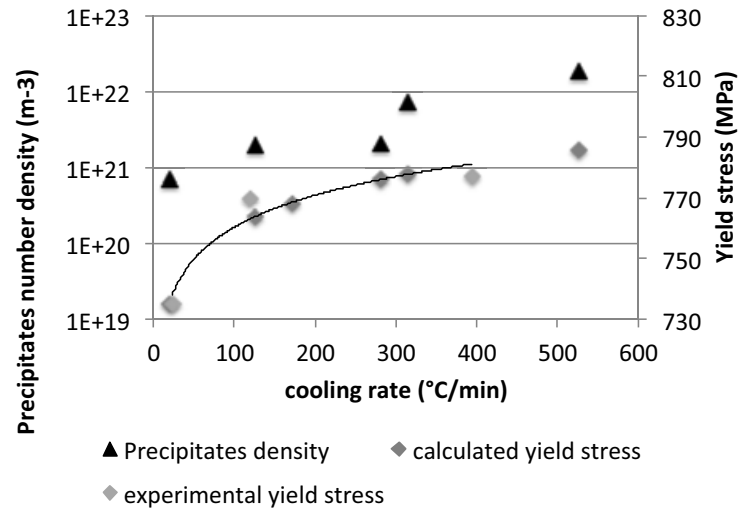

Figure 10. Evolution of number density of precipitate and yield stress at $20^{\circ} \mathrm{C}$ according to the cooling rate.

iii) The average size, the average distance between particles as well as the number density of $\gamma^{\prime}$ precipitates are significantly modified by the cooling rate. These differences may induce stress gradients during cooling of large parts.

iv) The total volume fractions of the $\gamma^{\prime}$ phase after annealing remain quite far from the fraction calculated at thermodynamic equilibrium. The question of the thermo-mechanical conditions to reach the equilibrium has not yet been addressed in this study.

The two main outlooks are:

- Firstly to derive a predictive model in order to estimate residual stresses after cooling from the annealing temperature. The selected model is a viscoelastoplastic additive model originally developed by Chaboche and Lemaitre [13]. The main goal is to include a microstructural parameter, which depends on the cooling rate for the investigated range.

- Secondly to analyze possible thermo-mechanical conditions that could induce an additional precipitation, which brings closer to the thermodynamic equilibrium. In particular, the influence on the $\gamma^{\prime}$ precipitation of a sufficient stress applied at high temperature should be analyzed.

These outlooks will be developed in further articles. 


\section{References}

[1] M. P. Jackson, R. C. Reed, Mater. Sci. Eng. A, 259, 85-97, (1999)

[2] D. U. Furrer, Scripta Mater., 40, 1215-1220, (1999)

[3] A. R. P. Singh, S. Nag, S. Chattopadhyay, Y. Ren, J. Tiley, G. B. Viswanathan, H. L. Fraser, R. Banerjee, Acta Mater., 61, 280-293, (2013)

[4] J. Mao, K. Chang, W. Yang, K. Ray, S. P. Vaze, D. U. Furrer, Metal. and Mater. Trans. A, 32, (2001)

[5] W. M. Kane, U. Krupp, T. Jacobs, C. J. McMahon, Mater. Sci. Eng. A, 402, 42-46, (2005)

[6] J. Mao, K.-M. Chang, D. Furrer, Superalloys 2000 (Ninth Int. Symp.), 109-116, (2000)
[7] D. M. Collins, L. Yan, E. A. Marquis, L. D. Connor, J. J. Ciardiello, A. D. Evans, H. J. Stone, Acta Mater., 61, 7791-7804, (2013)

[8] B. M. B. Grant, E. M. Francis, J. Q. da Fonseca, M. Preuss, M. R. Daymond, Mater. Sci. Eng. A, 573, 54 61, (2013)

[9] T. Grosdidier, A. Hazotte, A. Simon, Mater. Sci. Eng. A, 256, 183-196, (1998)

[10] C. Bellot, P. Lamesle, J. Alloys Compd., vol. 570, pp. 100-103, Sep. 2013

[11] H. Monajati, M. Jahazi, R. Bahrami, S. Yue, Mater. Sci. Eng. A, 373, 286-293, (2004)

[12] M. Perrut, M.-H. Mathon, D. Delagnes, J. Mater. Sci., 47, 1920-1929, (2011)

[13] LEMAITRE, J.-L. CHABOCHE, Mécanique des matériaux solides, 123-341 (1996) 